\title{
Efeitos dos eventos extremos climáticos na variabilidade hidrológica em um rio de Ecossistema Tropical Amazônico
}

As chuvas influenciam a dinâmica hidrológica nos rios amazônicos (enchente, cheia, vazante e seca). A dinâmica hidrológica influencia os organismos aquáticos e na infraestrutura logística, econômica e social das populações que habitam as margens dos rios amazônicos. Assim, estudos que investiguem a relação da precipitação pluvial com o nivel fluviométrico são necessário para entendermos essa dinâmica e melhorarmos as previsões dos modelos regionais de chuva-vazão. Para este estudo foram utilizados dados mensais de precipitação pluvial (PRP), número de dias com chuva (NDC) e nível do Rio Tapajós das estações fluviais e pluviais localizadas na cidade de Santarém/PA, os dados foram obtidos junto a Agência Nacional de Águas, para o período de janeiro de 1980 até dezembro de 2015. Foi calculada a correlação cruzada com os dados não normalizados, para identificar a defasagem com máxima relação entre a PRP/NDC e o nível do Rio. Em seguida, foram normalizadas as médias anuais de nível, para identificar anos com o nível abaixo, dentro e acima da média e por último foram calculadas médias mensais o nível do Rio. Em seguida, foram normalizadas as médias anuais de nivel, para identificar anos com o nivel abaixo, dentro e acima da média e por último foram calculadas médias mensais para cada uma das 3 categorias, e aplicado o teste t-student. Entre os principais resultados encontrados pode-se destacar: I) Os diagramas de caixas ('boxplot') mostram que todas as variáveis estudadas apresentam sazonalidade bem definida. O nível do Rio Tapajós apresenta período de máximos entre os meses de abril a junho, mínimos outubro a dezembro, e períodos de transição de janeiro a março e de agosto a setembro. Já a PRP e NDC apresenta pico entre janeiro a maio, estiagem de agosto a dezembro e transição em junho e julho; II) A correlaçã temporal de 2 a 3 meses entre a chuva a cota. A cota máxima do Rio Tapajós sofre grande variação nos anos de eventos extremos (estiagem ou chuva acima da média), quando se afasta da média histórica até $1 \mathrm{~m}$, porém, o mesmo não se verifica para a cota mínima, que permanece dentro da média histórica em anos de eventos extremos. Definiu-se o período hidrológico da regia : hei (abrla juho), vazante (julho a setembro), sca (oulbroa deza (a) atividades econômicas de pesca e agricultura de várzea, de lazer, turismo e transporte fluvial. Pode também orientar com antecedência as intervenções necessárias do governo municipal na orla da cidade, que frequentemente sofre inundação no período de cheia, podendo minimizar os danos causados.

Palavras-chave: Precipitação Pluvial; Nível fluviométrico; Rio Tapajós; Santarém/PA.

\section{Effects of extreme climate events on hydrological variability in a Amazon Tropical Ecosystem River}

\begin{abstract}
The rain influence the hydrological dynamics in Amazonian rivers (flood, spate, ebb and drought). Hydrological dynamic influences both aquatic organisms and the social, economic and logistics infrastructure of the inhabitants of the Amazon River banks. Thus, studies investigating the relationship between rainfall and the river level are needed to understand this dynami and improve predictions of regional rainfall-runoff models. In this study rainfall (PRP), number of days with rain (NDC) and the level of the Tapajós River in a monthly basis data were provided by river and rainfall stations located in the municipality of Santarém-PA. The data were obtained from the National Water Agency for the period January 1980 to December 2015 . The crosscorrelation was calculated with non-normalized data, to identify the gap with a maximum relationship between the PRP/NDC and the level of the river. Afterwards, the annual average leve was normalized, to identify years below, within and above the average level and at last monthly averages were calculated for each of the three categories, and the $t$-student test was applied. Among the mainfindngs can from January to May, dry season from August to December and transition in June and July; II) The maximum correlation between PRP/NDC and maximum level is with a lag of three months, with values greater than 0.6 much higher than the 0.3 the gap ' 0 '. It presented great time dependence 2-3 months between the rain quota. The maximum level of the Tapajós River undergoes wide variation in years of extreme events (drought or rain above average) when it deviates from the historical average by $1 \mathrm{~m}$, however, the same is not true for the minimum quota, which remains within the average historical in years of extreme events. Defined the hydrological period the region: full (April to July), low water (July to September), dry (October to December), flood (January to March). The study showed a consistent and predictable pattern of seasonal variation in the river level of the river, and its direct relationship with the rainfall. This predictability can be an important tool for the population, the annual planning of economic fishing activities and lowland agriculture, leisure, tourism and river transport. You can also guide in advance the necessary intervention of the municipal government on the edge of the city, which often suffers flooding in the rainy season, and can minimize the damage.
\end{abstract}

Keywords: Rainfall; River level; Tapajós River; Santarém/PA.

Topic: Meteorologia, Climatologia e Mudanças Climáticas

Reviewed anonymously in the process of blind peer.

Leidiane Leão de Oliveira (iD

Universidade Federal do Oeste do Pará, Brasil

http://lattes.cnpq.br/5016148560650320

http://orcid.org/0000-0002-5995-9107

leidianeoli@gmail.com

Naurinete de Jesus da Costa Barreto (iD)

Instituto Nacional de Pesquisas Espaciais, Brasil

http://lattes.cnpq.br/9415435965900811

http://orcid.org/0000-0001-5167-6228

netebarreto@gmail.com

Edmir dos Santos Jesus (it)

Universidade do Estado do Pará, Brasil

http://lattes.cnpq.br/5028749958173022

http://orcid.org/0000-0002-4383-5353

edmir.jesus@gmail.com

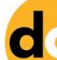

DOI: 10.6008/CBPC2179-6858.2020.004.0013
Received: 07/05/2020

Approved: 06/06/2020
Luis Gustavo de Castro Canani (iD

Instituto de Desenvolvimento Florestal e da Biodiversidade do Estado do Pará, Brasil

http://lattes.cnpq.br/6273864055158415

http://orcid.org/0000-0001-5508-7594

Igustavocc@gmail.com

Referencing this:

OLIVEIRA, L. L.; BARRETO, N. J. C.; JESUS, E. S.; CANANI, L. G. C.. Efeitos dos eventos extremos climáticos na variabilidade hidrológica em um rio de Ecossistema Tropical Amazônico. Revista Ibero Americana de Ciências Ambientais, v.11, n.4, p.145-153, 2020. DOI: http://doi.org/10.6008/CBPC2179-6858.2020.004.0013 


\section{INTRODUÇÃO}

As chuvas influenciam a dinâmica hidrológica nos rios amazônicos (enchente, cheia, vazante e seca). A dinâmica hidrológica influencia os organismos aquáticos (BENTES et al., 2018) e a infraestrutura logística, econômica e social das populações que habitam as margens dos rios amazônicos. A bacia Amazônia é a maior bacia hidrográfica do mundo, com uma área aproximada de $6000 \mathrm{~km}^{2}$ e tem 1100 afluentes, o que se dá por uma densa rede de drenagem entrecortando uma vasta região geográfica com rios, lagos e igarapés de pequeno a grande porte que compõem essa região (BRASIL, 2006).

De acordo com Carvalho et al. (2009) cidades com localização próximo a cursos d'água, sofrem de forma direta, as consequências do nível do rio, tanto de forma positiva, quanto de forma negativa, associado a eventos de enchentes e secas extremas. Conforme Filizola et al. (2006) Tais eventos ocorrem por conta da sazonalidade destes rios, cujos períodos sazonais se alternam entre períodos de águas altas (cheias) e águas baixas (secas). Outro fator importante, também são os períodos hidrológicos do Rio que se dividem entre enchente, cheia, seca e vazante, estudos de Bittencourt et al. (2007) apontam a influência da variação periódica do nível das águas, em organismos naturais de áreas de várzeas, que devido ao pulso de inundação, sincronizam seus ciclos biológicos para aproveitar os benefícios e/ou suportar as desvantagens decorrentes das mudanças no meio.

Para Silva et al. (2009) a precipitação pluviométrica é um dos elementos mais irregular espacial temporalmente. Sousa et al. (2000), afirma que na região Amazônica a variabilidade pluviométrica sazonal, apresenta dois períodos distintos, conhecidos como período chuvoso e seco ou menos chuvoso. Com base em estudos de Machado et al. (2010), as chuvas influenciam na infraestrutura e nos recursos naturais, sendo um fator determinante para ocorrência de erosões, enchentes e possíveis danificações de obras. Diante desta conjuntura o estudo das variáveis cota fluviométrica e precipitação pluviométrica são essenciais para criação de modelos hidrológicos de vazão dos rios.

De acordo com Marengo (2008), em relação à disponibilidade de recursos hídricos, o país possui posição privilegiada e a responsabilidade por grande parte dessa água é o clima. O ciclo anual de precipitações e de vazões varia entre bacias; a variabilidade interanual do clima está associada aos fenômenos de El Niño, La Niña, ou à variabilidade na temperatura da superfície do mar do Atlântico Tropical e Sul que podem gerar desequilíbrios climáticos. São compreendidas como eventos extremos as cheias e as secas. As cheias estão associadas com eventos de precipitação de grande magnitude, enquanto as secas se caracterizam pelo período com ausência de precipitações e altas temperaturas. Assim, o objetivo deste estudo foi investigar a relação da precipitação pluvial com o nível fluviométrico do rio Tapajós, em Santarém/PA. Informações como essas são necessárias para entendermos essa dinâmica e melhorarmos as previsões dos modelos regionais de chuva-vazão.

\section{METODOLOGIA}

\section{Área de Estudo}


A cidade de Santarém (PA) está localizada no Oeste paraense, na meso região do Baixo Amazonas, à margem direita do rio Tapajós, em confluência com o rio Amazonas, sob as coordenadas geográficas $2^{\circ} 24^{\prime} 52^{\prime \prime} \mathrm{S}$ e $54^{\circ} 42^{\prime} 36^{\prime \prime} \mathrm{W}$ (Figura 1). Santarém possui área territorial de aproximadamente $22.886,624 \mathrm{Km}^{2}$ de extensão, com uma população estimada em 294,447 habitantes (IBGE, 2010).

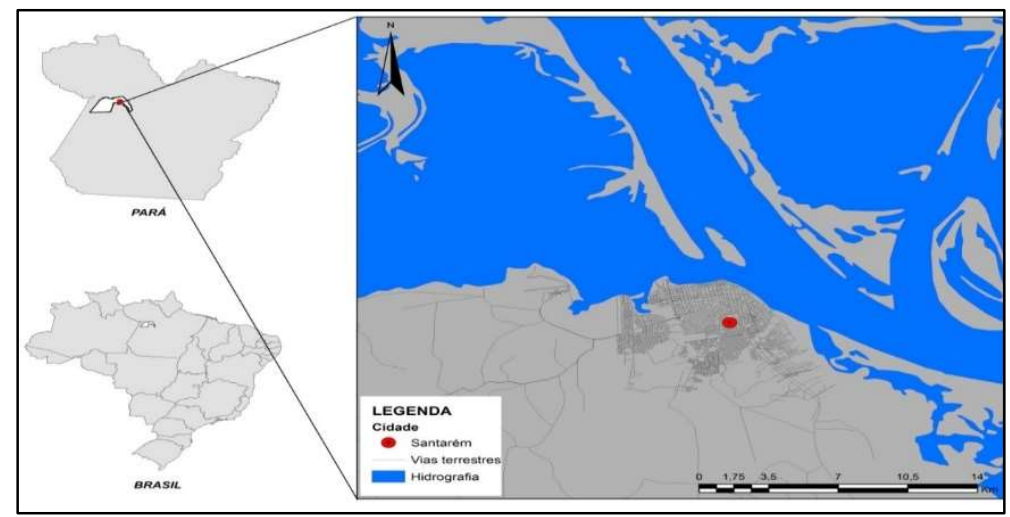

Figura 1: Localização geográfica da área de estudo, cidade de Santarém, Pará.

Santarém apresenta clima tropical úmido, com variação térmica anual inferior a $5^{\circ} \mathrm{C}$ e precipitação média anual em torno de 1820 mm (classe Ami conforme sistema Köppen). Ao contrário da temperatura, o regime de chuvas apresenta grande variação durante o ano, com o maior volume de precipitações ocorrendo nos meses de janeiro a maio. A vegetação de terra firme mais frequente é a Floresta Ombrófila Densa, vegetação dominante no norte do país e que abrange a maior parte dos estados do Pará, Amazonas, Amapá e Roraima.

\section{Precipitação Pluvial e Nível Fluviométrico do Rio Tapajós}

Para este estudo foram utilizados dados mensais de precipitação pluvial (PRP), número de dias com chuva (NDC) e nível do Rio Tapajós das estações fluvial e pluvial, localizadas na cidade de Santarém/PA. Os dados foram obtidos junto a Agência Nacional de Águas, para o período de janeiro de 1980 até dezembro de 2015. Vale ressaltar que houve mudança de local da estação fluviométrica no ano de 1999 o que provocou quebra de continuidade na série histórica. Então, foi evidenciado na análise anual do nível fluviométrico a avaliação antes e após a mudança de local.

Foi calculada a correlação cruzada com os dados não normalizados, para identificar a defasagem com máxima relação entre a PRP/NDC e o nível do Rio. Em seguida, foram normalizadas as médias anuais de nível, para identificar anos com o nível abaixo, dentro e acima da média e por último foram calculadas médias mensais para cada uma das três categorias, e aplicado o teste t-student. As respectivas análises estatísticas e saídas gráficas foram realizadas em linguagem " $R$ " (R CORE TEAM, 2014). O município de Santarém (PA), está sob influência do clima tropical úmido, com variação térmica anual inferior a $5^{\circ} \mathrm{C}$ e precipitação média anual em torno de $1820 \mathrm{~mm}$ (classe Ami conforme sistema Köppen). Ao contrário da temperatura, o regime de chuvas apresenta grande variação durante o ano, com o maior volume de precipitações ocorrendo nos meses de janeiro a maio. A vegetação de terra firme mais frequente é a Floresta Ombrófila Densa, vegetação dominante no norte do país e que abrange a maior parte dos estados do Pará, Amazonas, Amapá e Roraima. 


\section{RESULTADOS}

Entre os principais resultados encontrados se pode destacar: I) Todas as variáveis estudadas apresentam sazonalidade bem definida. O nível do Rio Tapajós apresenta período de máximos entre os meses de abril a junho, a mediana fica em torno de $600 \mathrm{~cm}$ (abril a junho) (Figura 2). A distância entre os máximos e mínimos demonstra que existe variabilidade interanual muito intensa na região. Como exemplo, o mês de maio é o que apresenta maior flutuação (variabilidade) do período de cheia na região; as oscilações são bem maiores, com máximo de $800 \mathrm{~cm}$ e mínimo de $380 \mathrm{~cm}$. Já nos meses de nível mais baixo (outubro a dezembro), em novembro a mediana fica em torno de $200 \mathrm{~cm}$. As oscilações no mês de novembro são bem menores, com máximo de $300 \mathrm{~cm}$ e mínimo em torno de $0 \mathrm{~cm}$. Os períodos de transição compreendem os meses de janeiro a março e de agosto a setembro (Figura 2).

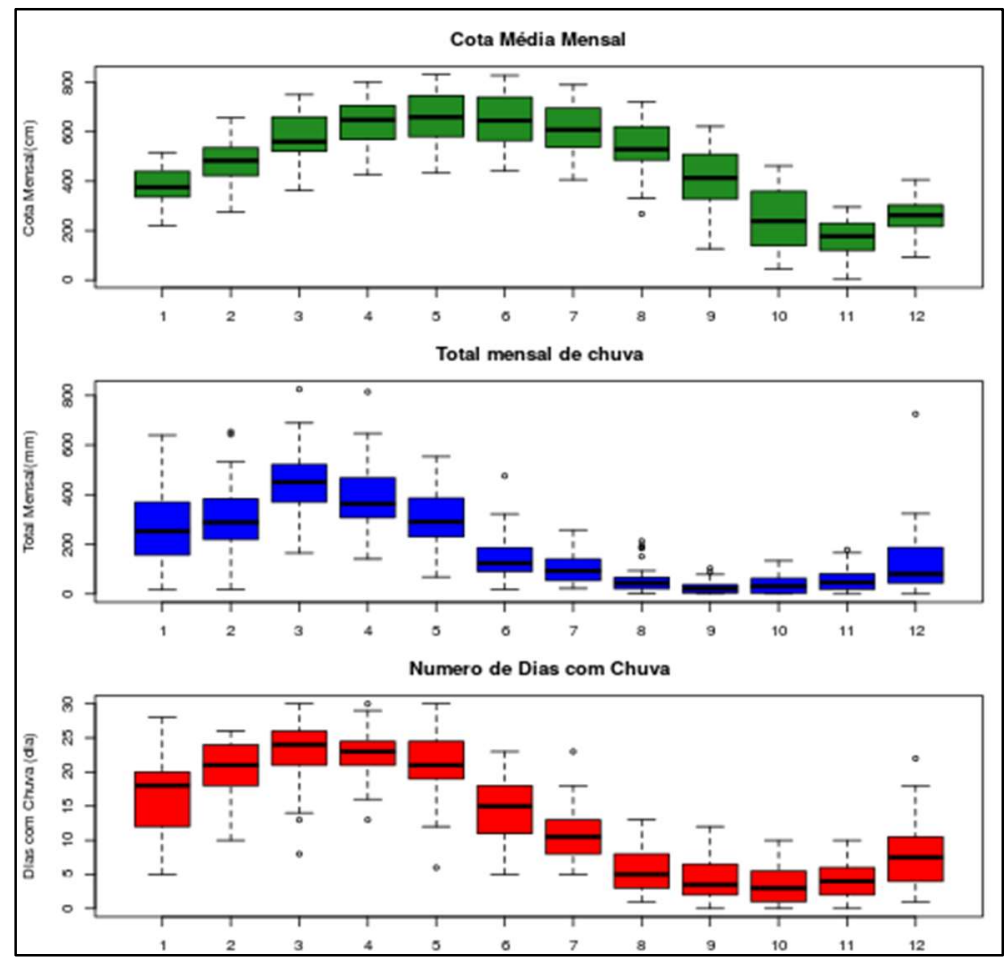

Figura 2: Diagrama 'boxplot' dos dados mensais de Nível do Rio do Tapajós, precipitação pluvial (painel central) e Número de dia com chuva - NDC (painel inferior) para Santarém/PA.

Já a Precipitação Pluvial - PRP e o Número de Dias com Chuva - NDC apresentam picos entre janeiro e maio. O mês de março é o mês mais chuvoso, com mediana 450 mm; o NDC fica em torno de 24. Em março as oscilações são maiores, com máximo de $700 \mathrm{~mm}$ e mínimo $170 \mathrm{~mm}$. Definiu-se o período hidrológico da região: cheia (abril a junho), vazante (julho a setembro), seca (outubro a dezembro), enchente (janeiro a março). Nos meses mais secos, setembro, outubro e novembro, a mediana da PRP ficou em torno de $50 \mathrm{~mm}$ e NDC em torno de 5 dias (Figura 2).

Em um segundo momento foi constatado que a correlação máxima entre PRP/NDC e Nível fluviométrico é máxima com defasagem de três meses, com valores superiores a 0,6, muito maior do que os 0,3 da defasagem ' 0 '. Assim, apresentou grande dependência temporal de dois a três meses entre a chuva e o nível fluviométrico (Figura 3). 


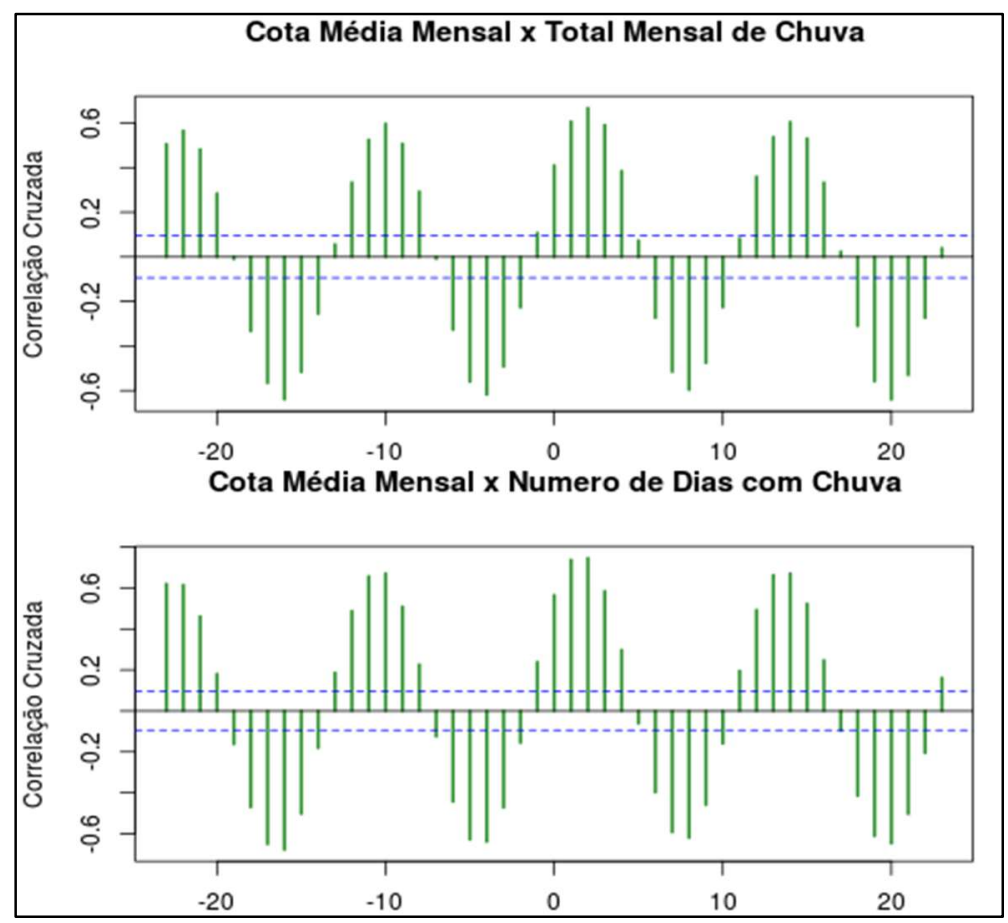

Figura 3: Correlação Cruzada entre Nível do Rio Tapajós pelo Total Mensal Precipitação pluvial (painel superior) e entre Nível do Rio Tapajós pelo Número de Dias com Chuva - NDC para Santarém/PA (painel inferior)

A cota máxima do Rio Tapajós sofre grande variação nos anos de eventos extremos (estiagem ou chuva acima da média), porém, o mesmo não se verifica para a cota mínima, que permanece dentro da média histórica em anos de eventos extremos (Figura 4). Foi possível detectar na série histórica a quebra de continuidade dos dados no ano de 2009, a percepção é que o nível do rio Tapajós aumentou a partir do ano de 2009, este fato se deve a mudança de localização da estação fluviométrica (Figura 4).

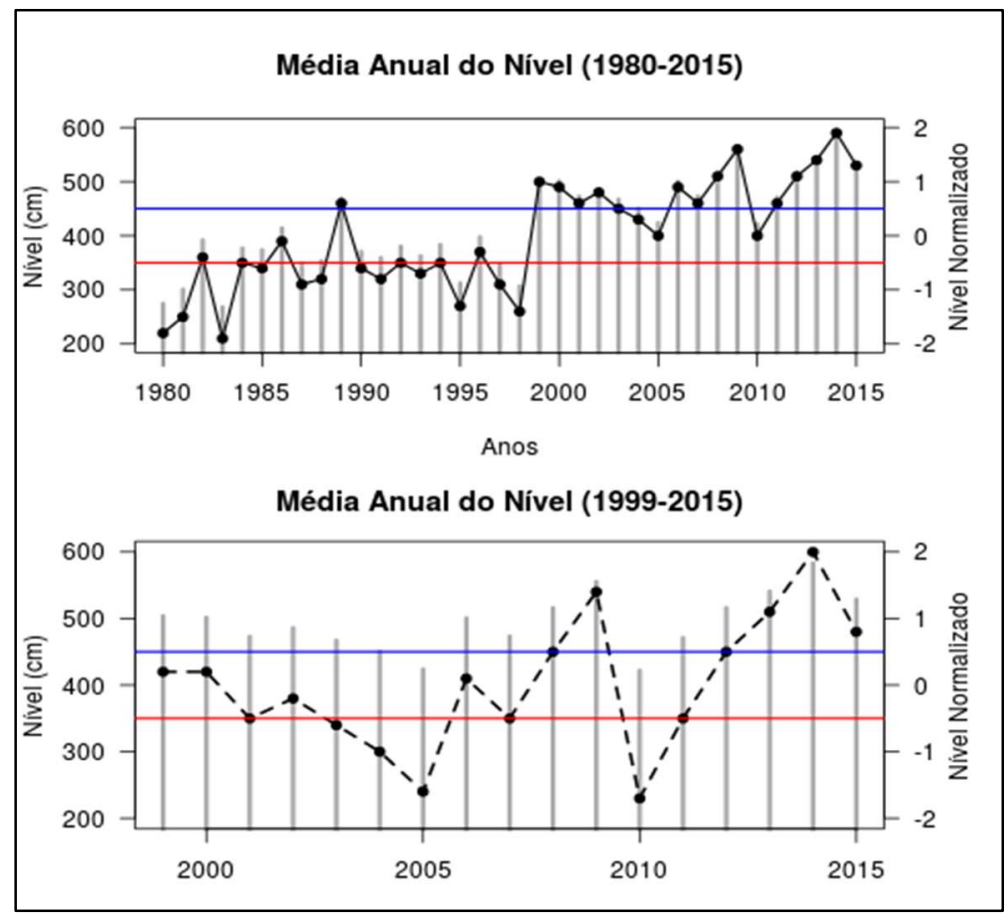

Figura 4: Média Anual do nível do Rio Tapajós, escala a esquerda valores médios, na escala a direita são os valores normalizados painel superior série histórica de 1980 a 2015 e painel inferior de 1999 a 2015. Média histórica para anos de cheia (linha azul) e média histórica de anos de seca (linha vermelha).

Foi possível detectar duas grandes cheias extremas nos anos de 2009 e 2014, enquanto, os anos de 
ocorrência de secas extremas são evidenciados em 2005 e 2010 (Figura 4). Podemos destacar que o recorde da média nível do rio para o ano de 2009 foi de $550 \mathrm{~cm}$ e para o ano de 2014 cerca de $600 \mathrm{~cm}$ (Figura 4). No painel superior da Figura 5 foi possível observar que na comparação entre as médias mensais dos anos de cheia (linha azul), seca (linha vermelha) e normais (linha preta) para nível do rio Tapajós em anos extremos de seca ou cheia o nível do rio se afasta $100 \mathrm{~cm}$ da média histórica.

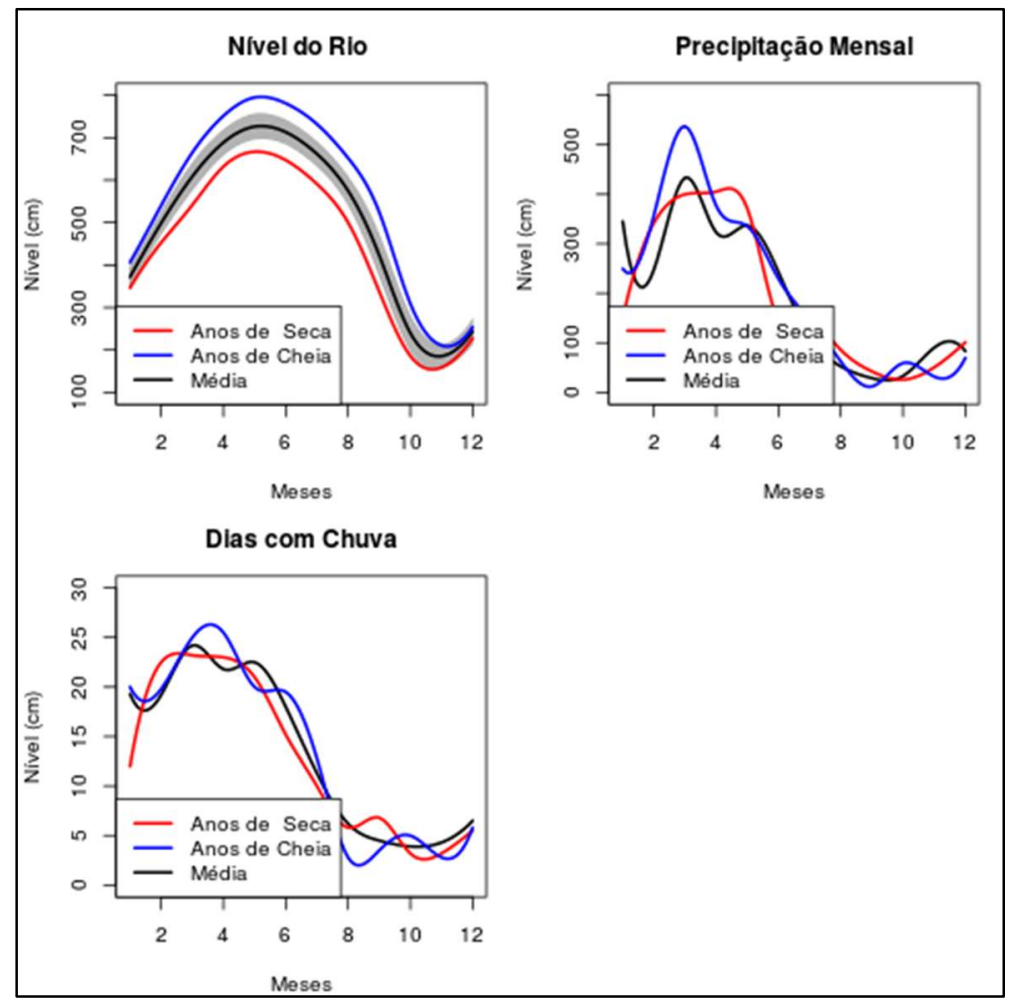

Figura 5: Comparação entre as médias mensais dos anos de cheia (linha azul), seca (linha vermelha) e normais (linha preta), (área cinza desvio padrão) para Nível do Rio Tapajós (painel superior à esquerda), Precipitação Mensal (painel superior direto) e Dias com Chuva (painel inferior esquerdo) para Santarém/PA.

Em anos normais, a cota máxima (maio) do rio Tapajós fica em torno de $700 \mathrm{~cm}$ (linha preta), $800 \mathrm{~cm}$ (linha azul) em anos de cheia e $600 \mathrm{~cm}$ (linha vermelha) em anos de seca (Figura 5 - painel superior esquerdo). A precipitação pluvial máxima ocorre no mês de março; em anos normais fica em torno de $450 \mathrm{~mm}$, em anos de cheia em torno de $550 \mathrm{~mm}$ e em anos de seca em torno de $380 \mathrm{~mm}$, enquanto que a precipitação mínima ocorre nos meses de setembro e outubro, fica abaixo de $50 \mathrm{~mm}$ (Figura 5 - painel superior direito).

No painel inferior esquerdo da Figura 5 foi possível observar que o número de dias com chuva máximo ocorre no mês de março, com média de 24 dias com chuva (linha preta). Em anos de cheia (linha azul), o mês de abril foi o que apresentou o maior número de dias com chuva, em média 27 dias. Enquanto, anos de seca (linha vermelha) apresentou 23 dias com chuva. Os menores valores de dias com chuva ocorrem no mês de outubro, média de 5 dias (linha preta), em anos de cheia sobe para 6 dias (linha azul) e anos de seca cai para 3 dias.

\section{DISCUSSÃO}

As variáveis estudadas apresentam sazonalidade bem definida. O nível do Rio Tapajós apresenta período de máximos entre os meses de abril a junho. O mês de maio é o que apresenta maior flutuação 
(variabilidade) do período de cheia na região. Já o mês de nível mais baixo é novembro. De acordo com Vale et al. (2019) o pico de cheia sempre se dá no mês de maio e o pico de seca no mês de novembro no rio Tapajós em Santarém/PA.

Definiu-se o período hidrológico da região: cheia (abril a junho), vazante (julho a setembro), seca (outubro a dezembro), enchente (janeiro a março) observados também por Santos et al. (2015). Outros estudos identificaram períodos bem definidos de águas altas e baixas para o rio Tapajós e regiões próximas (VALE et al., 2019; BENTES et al., 2018; ISAAC et al., 1995; ISAAC et al., 1996). Foi constatado uma defasagem em torno de dois a três meses entre a precipitação pluvial máxima que ocorre em Santarém com a cheia do rio Tapajós que ocorre apenas em maio (Figura 3).

O mês de março é o mês mais chuvoso, com mediana $450 \mathrm{~mm}$; o número de dias com chuva fica em torno de 24. O período chuvoso foi compreendido entre janeiro e maio. Nos meses mais secos, setembro, outubro e novembro, a mediana da PRP ficou em torno de $50 \mathrm{~mm}$ e o número de dias com chuva em torno de 5 dias. Março foi o mês que ocorreu o maior número de dias com chuva (24 dias). Com destaque para anos de cheia que o maior número de dias com chuva altera de março para abril. Enquanto outubro é o mês que apresenta o menor número de dias com chuva (5 dias). Podemos destacar os meses de setembro, outubro e novembro como sendo os mais secos, com apenas, média de 5 dias com chuva.

Foi verificado um período de verão e inverno amazônico no período de julho a novembro foi considerado seco e um período chuvoso de dezembro a maio. O período sazonal à região norte é determinado localmente como período de inverno (chuvoso) onde o volume de precipitação é elevado, e verão (estiagem) onde a quantidade de chuva é reduzida (NASCIMENTO et al., 2007; AMANAJÁS et al., 2015; ROSA et al., 2017). Segundo Silva et al. (2016), a precipitação pluvial média anual que ocorre na região de Santarém, no oeste do Pará é de 1920 mm, com maior intensidade no período de inverno que ocorre de dezembro a maio. Marengo et al. (2001), ao estudar as datas de início e fim da estação chuvosa da bacia amazônica e Estado do Pará, respectivamente, chegou a resultados semelhantes, definindo a data de início da estação chuvosa como sendo mais precoce no sul/sudeste da região e mais tardia próxima à foz do Rio Amazonas.

Neste estudo foi possível observar a ocorrência de 14 anos com eventos de cheias. Percebe-se que nos últimos 17 anos houve uma frequência de 70\% de eventos de grandes cheias na região de Santarém, incluindo o ano de 2017 (VALE et al., 2019). Destaque para as cheias extremas ocorrida no ano de 2009 e 2016 e secas extremas evidenciadas em 2005 e 2010. O rio Amazonas, durante a estação seca de 2016, foi influenciado por uma prolongada tendência climática do El Niño (2014, 2015 e 2016) (LIMA et al., 2019). Na cheia de 2009, o evento ocasionou o fenômeno de terras caídas nas comunidades ribeirinhas de Fátima do Urucurituba e Aninduba, o fenômeno mais intenso ocorreu em 2009, ano em que muitas casas, escolas e igrejas foram destruídas (VALE et al., 2019).

Em anos extremos de seca ou cheia o nível do rio se afasta $100 \mathrm{~cm}$ da média histórica. Os fenômenos climáticos chamados, dipolo do Atlântico, combinado com uma tendência para o aquecimento regional durante o evento El Niño ou La Niña (VALE et al., 2016) e o posicionamento da Zona de Convergência Inter 
Tropical - ZCIT podem estar associados aos eventos extremos de seca e cheias do Tapajós e Amazonas (LIMA et al., 2019; VALE et al., 2016).

\section{CONCLUSÕES}

O estudo demonstrou haver um padrão consistente e previsível de variação sazonal do nível fluviométrico do Rio Tapajós em Santarém/PA, e sua relação direta com a pluviosidade. Essa previsibilidade pode ser importante ferramenta para a população, no planejamento anual das atividades econômicas de pesca e agricultura de várzea, de lazer, turismo e transporte fluvial. Pode também orientar com antecedência as intervenções necessárias do governo municipal na orla da cidade, que frequentemente sofre inundação no período de cheia, podendo minimizar os danos causados.

\section{REFERÊNCIAS}

AMANAJÁS, J. C.; BRAGA, C. C.. Padrões espaço-temporal pluviométricos na Amazônia oriental utilizando análise multivariada. Rev. Bras. Meteorol, São Paulo, v.27, n.4, 2012. DOI: http://doi.org/10.1590/S010277862012000400006

BENTES, K. L. S.; OLIVEIRA, L. L.; ZACARDI, D. M.; BARRETO, N. J. C.. A relação entre a variação hidrológica e os recursos pesqueiros no baixo Amazonas, Santarém, Pará. Revista Brasileira de Geografia Física, v.11, p.234-238, 2018.

BITTENCOURT, M. M.; AMADIO, A. S.. Proposta para identificação rápida dos períodos hidrológicos em áreas de várzea do rio Solimões-Amazonas nas proximidades de Manaus. Acta Amazônica, v.37, n.2, p.303-308, 2007.

BRASIL. Ministério do Meio Ambiente. Caderno da Região Hidrográfica Amazônica. Brasília: Secretaria de Recursos Hídricos, 2006.

CARVALHO, V. R. O.; CARVALHO, A. C. C.; RANGEL, M. E. S. Análise do comportamento pluviométrico e sua relação com as cotas fluviais em eventos de enchentes na área urbana de bacabal no ano de 2009. Bacabal: Universidade Federal do Maranhão, 2009.

FILIZOLA, N.; GUYOT, J. L.; GUIMARÃES, V.. Measuring the discharge of the amazona River using doppler technology (Manacapuru, Amazonas, Brasil). Hydrological Processes, v.23, n.22, p.3151-3156, 2009.

ISAAC, V. J.; BARTHEM, R. B.. Os recursos pesqueiros da Amazônia brasileira. Bol. Mus. Para. Emílio Goeldi, v.11, p.295-339, 1995.

ISAAC, V. J.; MILSTEIN, A.; RUFFINO, M. L.. A Pesca Artesanal no Baixo Amazonas - Análise Multivariada das Capturas por Espécie. Acta Amazônica, v.26, p.185-208, 1996.

LIMA, N. S.; OLIVEIRA, A. M.; FILHO, E. B. F.; BRAGA, J. O. N.; FIGUEIREDO, R. S.; CALAZÃES, R. M.; QUISPE, W. D.; VALE, R. S.; FERREIRA, A. S.. Reduction In Water Levels And Regional Warming Of The Amazon River From Peru To The Atlantic Ocean In Brazil Due To The Effects Of The 2016 ENSO. Revista Brasileira De Geofísica, v.37, p.83-94-94, 2019.
MACHADO, R. L.; CEDDIA, M. B.; CARVALHO, B. F.; CRUZ, E. S.. Variabilidade espacial da chuva máxima diária anual média e sob diferentes períodos de retorno no estado do Rio de Janeiro, Brasil. Bragantia, v.69, p.77-84, 2010.

MARENGO, J. A.. Água e mudanças climáticas. Estudos Avançados, v.22, n.63, p.83-93, 2008.

MARENGO, J. A.; LIEBMANN, B.; KOUSKY, V. E.; FILIZOLA, N. P.; WAINER, I. C.. Onset and End of the Rainy Season in the Brazilian Amazon Basin. Journal of Climate, v.14, n.5, p.833852, 2001. DOI: http://doi.org/10.1175/15200442(2001)014<0833:OAEOTR>2.0.CO;2

NASCIMENTO, T. S.; SARAIVA, J. M. B.. Variabilidade Sazonal da Precipitação pluviométrica em cidades na calha do Rio Solimões, Amazonas. In: CONGRESSO BRASILEIRO DE ÁGUAS SUBTERRÂNEAS, 8. Anais. Belo Horizonte, 2007.

R CORE TEAM. R: A language and environment for statistical computing. Vienna: R foundation for statistical computing, 2014.

ROSA, A. G.; SANTOS, J. T. S.; COSTA, J. A.; FONSECA, D. D. F.; SOUSA, A. M. L.. Comportamento da precipitação como fator ativo de processos erosivos no município de Rondon do Pará, PA (Brasil). Scientia Plena, v.13, n.2, 2017. DOI: http://doi.org/10.14808/sci.plena.2017.025301

SANTOS, C.; ARAUJO, I.; WANZELER, R.; SERRÃO, E.; FARIAS, M.; LIMA, A.. Regionalização hidroclimatológica da bacia hidrográfica do rio Tapajós. Rev. Geogr. Acadêmica, v.9, n.1, p.32-51, 2015.

SILVA, L. L.; COSTA, R. F.; DANTAS, R. T.. Influência das precipitações na produtividade agrícola no Estado da Paraíba. Revista Brasileira de Engenharia Agrícola e Ambiental, v.13, n.4, p.454-461, 2009.

SILVA, M. A. G.; JÚNIOR, J. M. G.; SILVA, N. F. C.; SANTOS, F. C. V.; UCKER, F. E.. Caracterização pluviométrica de Santarém/PA, Brasil. Revista eletrônica de educação da faculdade Araguaia, v.4, n.10, p.112-120, 2016.

SOUZA, E.; KAYANO, M.; TOTA, J.; PEZZI, L.; FISCH, G.; NOBRE, C.. On the influences of the EI Niño, La Niña and 
Atlantic dipole pattern on the Amazonian rainfall during 1960-1998. Acta Amazônica, v.30, n.2, p.305-318, 2000.

VALE, R. S.; LIMA, L. S.; MONTE, C. N.; SANTANA, R. A. S.. Evidências do fenômeno de terras caídas com grandes cheias na região Oeste do Pará. Braz. J. of Develop., Curitiba, v.5, n.6, p.6295-6302, 2019.
VALE, R. S.; GOMES, A. C. S.; SANTANA, R. A. S.; TOTA, J.; MILLER, S. D.; SOUSA, R. A. F.. Hydroclimatic variables associated with El Nino and La Nina events at the Curuá-Una hydroelectric reservoir, Central Amazonia. Revista Acta Amazônica, v.46, p.03-308, 2016.

A CBPC - Companhia Brasileira de Produção Científica (CNPJ: 11.221.422/0001-03) detém os direitos materiais desta publicação. Os direitos referem-se à publicação do trabalho em qualquer parte do mundo, incluindo os direitos às renovações, expansões e disseminações da contribuição, bem como outros direitos subsidiários. Todos os trabalhos publicados eletronicamente poderão posteriormente ser publicados em coletâneas impressas sob coordenação da Sustenere Publishing, da Companhia Brasileira de Produção Científica e seus parceiros autorizados. Os (as) autores (as) preservam os direitos autorais, mas não têm permissão para a publicação da contribuição em outro meio, impresso ou digital, em português ou em tradução. 